\title{
DETERMINATION OF LOW CONCENTRATIONS OF URANIUM IN OILS AND ORGANIC LIQUIDS BY X-RAY EMISSION
}

T. T. Adams

T. H. Barton, Jr

M. R. Ferguson

\section{OAK RIDGE Y-12 PLANT} OAK RIDGE. TENNESSEE 


\section{DISCLAIMER}

This report was prepared as an account of work sponsored by an agency of the United States Government. Neither the United States Government nor any agency Thereof, nor any of their employees, makes any warranty, express or implied, or assumes any legal liability or responsibility for the accuracy, completeness, or usefulness of any information, apparatus, product, or process disclosed, or represents that its use would not infringe privately owned rights. Reference herein to any specific commercial product, process, or service by trade name, trademark, manufacturer, or otherwise does not necessarily constitute or imply its endorsement, recommendation, or favoring by the United States Government or any agency thereof. The views and opinions of authors expressed herein do not necessarily state or reflect those of the United States Government or any agency thereof. 


\section{DISCLAIMER}

Portions of this document may be illegible in electronic image products. Images are produced from the best available original document. 


\begin{tabular}{|c|}
\hline Printed in the United States of America. Available from \\
National Technical Information Service \\
U.S. Department of Commerce \\
5285 Port Royal Road, Springfield, Virginia 22151 \\
Price: Printed Copy \$3.00; Microfiche $\$ 0.95$ \\
\hline
\end{tabular}

This report was prepared as an account of work sponsored by the United States Government. Neither the United States nor the United States Atomic Energy Commission, nor any of their employees, nor any of their contractors, subcontractors, or their employees, makes any warranty, express or implied, or assumes any legal liability or responsibility for the accuracy, completeness or usefulness of any information, apparatus, product or process disclosed, or represents that its use would not infringe privately owned rights.

Reference to a company or product name does not imply approval or recommendation of the product by Union Carbide Corporation or the U S Atomic Energy Commission to the exclusion of others that may meet specifications. 


\title{
DETERMINATION OF LOW CONCENTRATIONS OF URANIUM IN OILS AND ORGANIC LIQUIDS BY X-RAY EMISSION
}

\author{
.T. T. Adams \\ T. H. Barton, Jr \\ M. R. Ferguson
}

Oak Ridge Y-12 Plant

P.O. Box Y, Oak Ridge, Tennessee 37830

operated for the U.S. ATOMIC ENERGY COMMISSION bY UNION CARBIDE CORPORATION-NUCLEAR DIVISION

under Contract W-7405-eng-26

\begin{abstract}
This report was prepared as an account of work sponsored by the United States Government. Neither the United States nor the United States Atomic Energy Commission, nor any of their employees, nor any of their contractors, subcontractors, or their employees, makes any warranty, express or implied, or assumes any legal liability or responsibility for the accuracy, completeness or usefulness of any information, apparatus, product or process disclosed, or represents that its use would not infringe privately owned rights.
\end{abstract}

Date Issued - October 17, 1972 


\begin{abstract}
An improved method has been developed for determining the concentration of uranium in organic liquids by $\mathrm{X}$-ray emission. The method is applicable to uranium concentrations in the range of 10 to 2,000 micrograms per milliliter.
\end{abstract}


CONTENTS

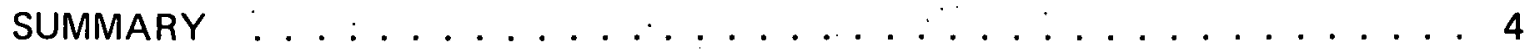

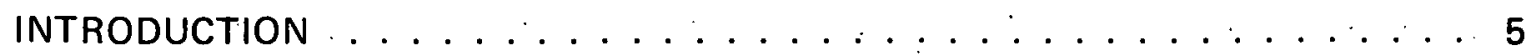

METHOD FOR URANIUM DETERMINATION BY X-RAY EMISSION . . . . . . . . . 6

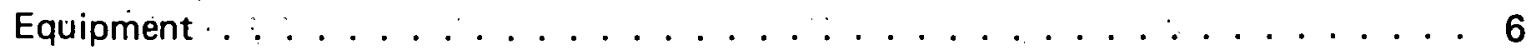

X-Ray Emission Spectrometer $\quad \ldots \ldots \ldots \ldots$

Balance . . . . . . . . . . . . . . . . . . . 6

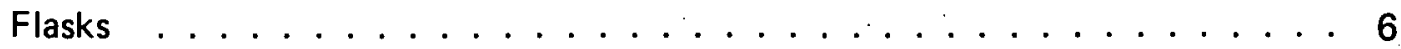

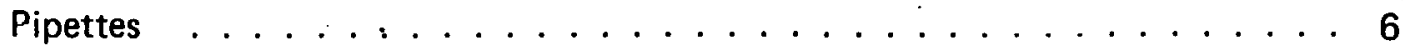

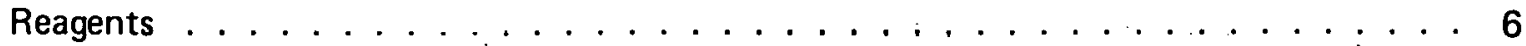

Preparation of Standard Solutions . . . . . . . . . . . . . . . 6

Stock Solutions . . . . . . . . . . . . . . . . . 6

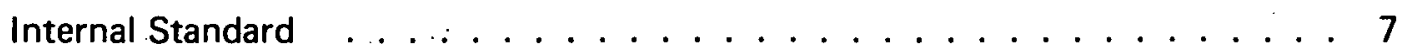

" $A$ " Working Standards for Carbitol, Oils, and Tributylphosphate . . . . . . . 7

"B" Working Standard for Chlorinated Solvents and Coolants . . . . . . . . . . 7

Instrument Parameters . . . . . . . . . . . . . . . . . 7

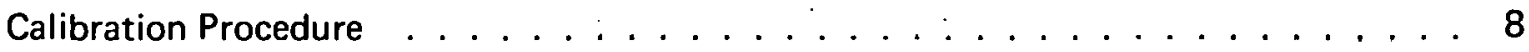

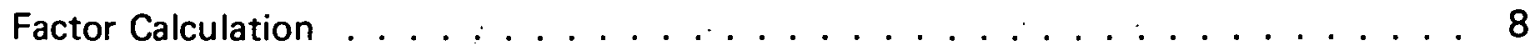

Sample Preparation ...................... 8

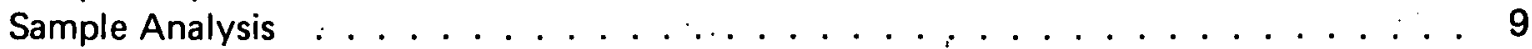

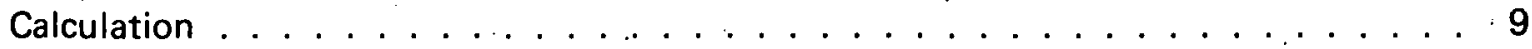

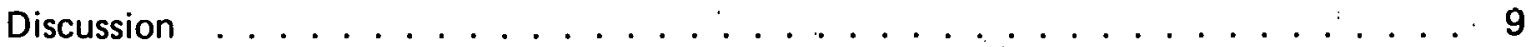

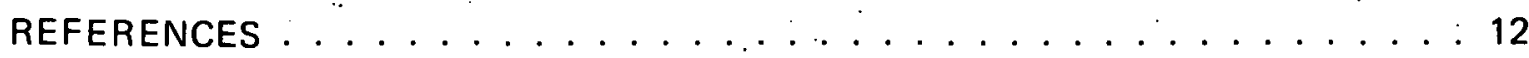




\section{SUMMARY}

$X$-ray emission affords a rapid means for analyzing various materials for uranium. However, the established laboratory procedure for the analysis of organic liquids suffered from poor precision and lack of sensitivity. A method has been developed that eliminates these objections and reduces standardization time. This method consists of diluting the sample with diethylene glycol dibutyl ether (dibutyl Carbitol) containing a known amount of $1,3,5$-tribromobenzene as an internal standard and analyzing by $X$-ray emission. The bromine $K a_{1}$ line is used as the internal standard for $U_{L a_{1}}$. The new procedure is valid over a concentration range of 10 to $2,000 \mu \mathrm{gs} \mathrm{U} / \mathrm{ml}$ in various liquid organics and has a relative limit of error (0.95) of \pm 2.5 percent for a single analysis. 


\section{INTRODUCTION}

The Y-12 Plant Laboratory (a) analyzes a wide variety of organic liquids for uranium. These liquids include diethylene glycol dibutyl ether (dibutyl Carbitol) and tributyl phosphate (TBP) from extraction processes, lubricating oils, such solvents as perchloroethylene and trichloroethylene, and mixtures of oils and chlorinated solvents used as machine coolants. The established procedure $(1)$ for determining low concentrations of uranium in these materials by $\mathrm{X}$-ray emission utilizes an aqueous solution of yttrium as an internal standard. This solution has to be physically mixed with the sample in an inert powder since the aqueous and organic phases are not miscible. Because it is difficult to make the resulting mixture homogeneous, precision is relatively poor. An investigation was therefore in order to find a more suitable means for adding the internal standard. When attempts to add the yttrium in an organic form proved unsatisfactory, a substitute internal standard was sought. Of the several possibilities, bromine appeared to be the most attractive. Pish and Huffman (2) successfully used bromine as an internal standard for thorium and uranium, but limited their work to the analysis of tributyl phosphate. Experimentation showed that a Carbitol solution of 1,3,5-tribromobenzene provided a satisfactory medium for adding bromine to all the various types of organic liquids received by the laboratory.

(a) The Oak Ridge Y-12 Plant is operated by the Union Carbide Corporation's Nuclear Division for the US Atomic Energy Commission. 


\section{METHOD FOR URANIUM DETERMINATION BY X-RAY EMISSION}

\section{EQUIPMENT}

\section{X-Ray Emission Spectrometer}

The spectrometer is equipped with a molybdenum target tube, a lithium fluoride analyzing crystal, a scintillation detector and associated counting equipment, and a $13 / 8$-inch-diameter Teflon sample cup.

\section{Balance}

An analytical balance is used.

Flasks

Volumetric flasks of $50,100,250$, and 500-milliliter capacity are needed.

Pipettes

Use volumetric pipettes of 5, 10, 20, and 25-milliliter capacity.

\section{REAGENTS}

The following reagent-grade solutions are needed: diethylene glycol dibutyl ether (dibutyl Carbitol), nitric acid, 1,3,5-tribromobenzene, and tributyl phosphate (TBP). In addition, USP Grade trichloroethylene and high-purity $(0.999+)$ uranium metal are required.

\section{PREPARATION OF STANDARD SOLUTIONS}

\section{Stock Solutions}

The necessary stock solutions have the concentrations and methods of preparation as follows:

$\begin{array}{cc}\text { Solution } & \begin{array}{c}\text { Concentration } \\ (\mu \mathrm{gs} \mathrm{U} / \mathrm{ml})\end{array} \\ 1 & 10,000 \\ 2 & 5,000 \\ 3 & 1,000 \\ 4 & 100\end{array}$

Preparation Procedure

Five grams of uranium metal dissolved in dilute nitric acid, evaporated to near dryness, then redissolved in 500 milliliters of Carbitol.

Two and one-half grams of uranium metal prepared in the same manner as Solution 1.

One-half gram of uranium metal prepared in the same manner as Solution 1.

Twenty-five milliliters of Solution 3 made to 250 milliliters with Carbitol. 


\section{Internal Standard}

The internal standard is prepared by dissolving 1.9 grams of 1,3,5-tribromobenzene in 1,000 milliliters of diethylene glycol dibutyl ether.

\section{"A" Working Standards for Carbitol, Oils, and Tributylphosphate}

The " $A$ " working standards have the concentrations and methods of preparation as follows:

\begin{tabular}{|c|c|}
\hline $\begin{array}{l}\text { Concentration } \\
(\mu \mathrm{gs} U / \mathrm{ml})\end{array}$ & Preparation Procedure \\
\hline 2,000 & 20 Milliliters of Stock Solution 1 \\
\hline 1,000 & 10 Milliliters of Stock Solution 1 \\
\hline 500 & 10 Milliliters of Stock Solution 2 \\
\hline 250 & 25 Milliliters of Stock Solution 3 \\
\hline 100 & 10 Milliliters of Stock Solution 3 \\
\hline 50 & 5 Milliliters of Stock Solution 3 \\
\hline 10 & 10 Milliliters of Stock Solution 4 \\
\hline
\end{tabular}

Pipette each standard into a 100-milliliter volumetric flask, add 20 milliliters of the internal standard, dilute to volume with diethylene glycol dibutyl ether, and mix thoroughly.

\section{"B" Working Standards for Chlorinated Solvents and Coolants}

Note: Prepare these standards fresh every time samples of this type are analyzed. Use the same schedule as for the " $A$ " working standards. Pipette each standard into a 100-milliliter volumetric flask, add 50 milliliters of trichloroethylene, 20 milliliters of the internal standard, then dilute to volume with diethylene glycol dibutyl ether and mix thoroughly.

\section{INSTRUMENT PARAMETERS}

Instrument parameters have been determined and are as follows:

$\begin{array}{ll}\text { Excitation } & 50 \mathrm{kv}-15 \mathrm{ma} \\ \text { Crystal } & \text { LiF } \\ \text { Detector Voltage } & 900 \\ \text { Course Gain } & 64 \\ \text { 'Fine Gain } & 5.5 \\ \text { Upper Level } & 1.30 \\ \text { Lower Level } & \therefore \\ \text { Time } & 0.075 \\ \text { Goniometer } & 50 \text { seconds } \\ & 26.14^{\circ} 2 \theta\left(\mathrm{U}_{\mathrm{La}}\right) \\ & 28.70^{\circ} 2 \theta\left(\mathrm{Bkg}_{1}\right) \\ & 29.93^{\circ} 2 \theta \cdot\left(\mathrm{Br}_{\mathrm{Ka}}\right)\end{array}$




\section{CALIBRATION PROCEDURE}

Proper calibration is accomplished by observing the following steps:

1. Set the X-ray generator for $50 \mathrm{kv}$ and $15 \mathrm{ma}$ and allow a few minutes for the $\mathrm{X}$-ray beam to stabilize.

2. Set the pulse height analyzer to the proper conditions for uranium.

3. Rinse the Teflon sample cup with the standard, then pour about 10 milliliters of the standard into the cup and cover the cup with a Teflon cover. Position the specimen in the $X$-ray beam.

4. Count at $26.4^{\circ} 2 \theta(\mathrm{U})$ for 50 seconds, $28.70^{\circ} 2 \theta(\mathrm{Bkg})$, and $29.93^{\circ} 2 \theta(\mathrm{Br})$ for 50 seconds.

5. Obtain the net counts for 50 seconds for $U$ and $\mathrm{Br}$ by subtracting the background (c/50 $\mathrm{sec})$ from the gross peak (c/50 sec).

6. Calculate the intensity ratio: $R=\frac{U \mathrm{c} / 50 \mathrm{sec}}{\mathrm{Brc} / 50 \mathrm{sec}}$.

7. Count all standards and calculate a factor.

\section{FACTOR CALCULATION}

Calculate the relationship between the intensity ratio and concentration of standards. The equation should be of the form: $Y=m X+b$ where: $Y$ represents the concentration in $\mu \mathrm{gs} / \mathrm{ml}, \mathrm{X}$ the intensity ratio, $\mathrm{m}$ the slope of the calibration curve, and $\mathrm{b}$ the intercept of the calibration curve.

\section{SAMPLE PREPARATION}

Samples are prepared as follows:

1. Tare a clean 50-milliliter volumetric flask.

2. Pipette. 25 milliliters of the sample into the tared volumetric flask. Note: On some samples, such as heavy oils, it may be necessary to pour the sample into the volumetric flask through a funnel because of its high viscosity.

3. Obtain the gross weight.

4. Add 10 milliliters of the internal standard.

5. Dilute the sample to volume with Carbitol and mix thoroughly. 


\section{SAMPLE ANALYSIS}

Analysis of the sample is accomplished as follows:

1. Follow Steps 1 thröugh 6 of the CALIBRATION PROCEDURE.

2." For Carbitol, oil, and TBP samples, use the " $A$ " working standards calibration curve. (Prepare a blank for the TBP samples by pipetting 25 milliliters of tributyl phosphate and 10 milliliters of the internal standard into a clean, 50-milliliter volumetric flask, then dilute to volume with diethylene glycol dibutyl ether and mix thoroughly.)

3. For chlorinated solvents and coolants, use the " $B$ " working standards calibration curve.

\section{CALCULATION}

Calculation of the uranium concentration can be accomplished by using the equation:

$$
C=\frac{(R \times F)+1}{W} \times V
$$

where:
C . represents the concentration of uranium in grams per gram of sample,
$\mathrm{R}$ the $\mathrm{U}_{\mathrm{L} a_{1}} / \mathrm{Br}_{\mathrm{K} a_{1}}$ intensity ratio,
F the slope of the calibration curve,
$W$ the sample weight in grams, and
$V$ the volume of the volumetric flask.

For tributylphosphate samples, calculate the apparent uranium concentration in the TBP blank by using the equation and then subtracting this value from the calculated sample result to obtain the uranium concentration of the sample.

\section{DISCUSSION}

The established method for determining low concentrations of uranium in organics uses an aqueous solution of yttrium as an internal standard. $\dot{Y}$ ttrium is an ideal internal standard for uranium and is currently being used in several other procedures requiring the determination of uranium concentrations. However, physical mixing of an aqueous internal standard with an organic is not practical because it is not possible to obtain a homogeneous solution from the two phases, and the inhomogeneity will increase with time.

Using an organic form of yttrium was suggested and investigated. The internal standard selected was yttrium acetate dissolved in Carbitol. Results of these investigations showed vast improvements in accuracy, precision, and the detection limit, but it was found that 
yttrium acetate, which had to be synthesized in the laboratory and dissolved in Carbitol, was not stable for long periods of time.

Table 1

URANIUM IN CARBITOL STANDARDS

\begin{tabular}{crrrr}
\hline $\begin{array}{c}\text { Standard } \\
\text { Concentration } \\
(\mu \mathrm{gs} \mathrm{U} / \mathrm{ml})\end{array}$ & \multicolumn{4}{c}{ Analytical Results $(\mu \mathrm{gs} \mathrm{U} / \mathrm{ml})$} \\
\cline { 2 - 5 } & Day 1 & \multicolumn{1}{c}{ Day 2 } & \multicolumn{1}{c}{ Day 3 } & Day 4 \\
\hline 2,000 & 1,965 & 1,972 & 1,964 & 1,995 \\
1,000 & 996 & 1,003 & 985 & 1,017 \\
500 & 500 & 501 & 500 & 500 \\
250 & 251 & 248 & 247 & 252 \\
100 & 105 & 103 & 99 & 98 \\
50 & 47 & 53 & 46 & 47 \\
10 & 10 & 9 & 10 & 11 \\
\hline
\end{tabular}

It was then decided to investigate the use of bromine as the internal standard since organic bromides are not likely to appear in samples being analyzed for uranium. The organic compound 1,3,5-tribromobenzene was selected and dissolved in Carbitol for use as a possible internal standard.

The $X$-ray fluorescence spectrometer used in this investigation was calibrated using synthetic standards prepared on a. metal-tometal basis following the proposed procedure. Each series of standards were then analyzed by this method for four different days. The resulting data are presented in Tables 1 and 2.

Using 1,3,5-tribromobenzene as an internal standard proved to be a much faster and more accurate method than the existing procedure. With this internal standard, the organic solution is completely homogeneous and it is possible to prepare standards and samples well in advance, except for those liquids containing chlorine. Within a few hours after adding the bromine internal standard to chlorinated organic liquids, the uranium-to-bromine intensity ratio begins to change significantly and continues to change over a period of several days. The cause of this phenomenon has not been
Table 2

URANIUM IN TRICHLOROETHYLENE STANDARDS

\begin{tabular}{crrrr}
\hline $\begin{array}{c}\text { Standard } \\
\text { Concentration } \\
(\mu \mathrm{gs} U / \mathrm{ml})\end{array}$ & \multicolumn{4}{c}{ Analytical Results $(\mu \mathrm{gs} \mathrm{U/ml)}$} \\
\cline { 2 - 5 } & Day 1 & Day 2 & Day 3 & Day 4 \\
\hline 2,000 & 2,008 & 1,981 & 2,040 & 2,015 \\
1,000 & 1,055 & 978 & 995 & 958 \\
500 & 500 & 500 & 500 & 500 \\
100 & 102 & 100 & 102 & 93 \\
50 & 50 & 49 & 52 & 53 \\
10 & 11 & 10 & 10 & 10 \\
\hline
\end{tabular}

Table 3.

CARBITOL LABORATORY CONTROL SAMPLE (Concentration: $758 \mu \mathrm{gs} \mathrm{U/ml)}$

\begin{tabular}{|c|c|c|c|}
\hline Date & 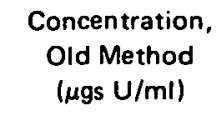 & Date & $\begin{array}{l}\text { Concentration } \\
\text { New Method } \\
\text { ( } \mu \mathrm{gs} \mathrm{U} / \mathrm{ml} \text { ) }\end{array}$ \\
\hline 7.01 .71 & 688 & $10-12 \cdot 71$ & 761 \\
\hline $7-06-71$ & 699 & 10-26-71 & 757 \\
\hline $7-08-71$ & 725 & $10-28-71$ & 775 \\
\hline $7 \cdot 20.71$ & 681 & $11-04-71$ & 766 \\
\hline $7-22-71$ & 708 & $11-09 \cdot 71$ & 765 \\
\hline $7-27-71$ & 791 & $11-11-71$ & 776 \\
\hline $7-29-71$ & 759 & $11-16.71$ & 782 \\
\hline $8-03-71$ & 812 & $11-18-71$ & 746 \\
\hline $8-05-71$ & 753 & $11-23-71$ & 749 \\
\hline $8 \cdot 10-71$ & 698 & $11-30-71$ & 766 \\
\hline $8-12 \cdot 71$ & 750 & $12-02.71$ & 751 \\
\hline $8-17-71$ & 718 & $12-07.71$ & 762 \\
\hline $8-19-71$ & 705 & $12 \cdot 09-71$ & 762 \\
\hline $8+24-71$ & 737 & $12-14-71$ & 781 \\
\hline $8-26-71$ & 719 & $12-16-71$ & 770 \\
\hline $8-31-71$ & 732 & $12 \cdot 21.71$ & 771 \\
\hline $9-02-71$ & 703 & $12-28-71$ & 766 \\
\hline $9-14-71$ & 744 & $12-30-71$ & 762 \\
\hline $9-16-71$ & 738 & $1.04-72$ & 758 \\
\hline $9-21-71$ & 716 & $1-06-72$ & 766 \\
\hline $9-23-71$ & 701 & $1-11-72$ & 772 \\
\hline $9-28-71$ & 679 & $1-13-72$ & 774 \\
\hline 9-30-71 & 791 & $1-18-72$ & 781 \\
\hline $10-05-71$ & 727 & 1.20 .72 & 764 \\
\hline $10-07-71$ & 764 & $1-27-72$ & 771 \\
\hline Mean & 729 & & 766 \\
\hline $\begin{array}{l}\text { LE }(0.95) \\
\text { of Mean }\end{array}$ & \pm 14 & & \pm 4 \\
\hline $\begin{array}{l}\text { Absolute } \\
\text { LE (0.95) } \\
\text { of a Single }\end{array}$ & . & & \\
\hline Analysis & \pm 72 & & \pm 19 \\
\hline
\end{tabular}


investigated thoroughly, but it is probably due to a slow reaction between the bromine and chlorine. For this reason, the internal standard should be added to chlorinated samples and standards just prior to analysis.

Estimated time savings for calibration by this new method is at least 50 percent. Calibration time is much longer with the old method as it is necessary to prepare standards every day. In addition, they can only be counted one time and both standards and samples have to be counted immediately after preparation.

As a control measure, the Quality Control Laboratory submits samples of a Carbitol batch containing 758 micrograms of uranium per milliliter with each group of production samples. Results obtained by the old and new methods on these samples over a period of three months are presented in Table 3. 


\section{REFERENCES}

(1) Walden, G. E. and Keyes, J. H.; The Detection of Small Quantities of Uranium in Various Liquid Organic Matrices by X-Ray Emission Spectroscopy, Y-DA-497; Union Carbide Corporation-Nuclear Division, Oak. Ridge Y-12 Plant, Oak Ridge, Tennessee; November 27, 1963.

(2) Pish, G. and Huffman, A. A.; "A Quantitative Determination of Thorium and Uranium in Solutions by Fluorescent X-Ray Spectrometry", Anal Chem, 27, pp 1875-1878 (1955). 


\section{DISTRIBUTION}

Atomic Energy Commission-ORO

Hickman, H. D.

Zachry, D. S., Jr

Oak Ridge Gaseous Diffusion Plant

Barton, J. C.

Wilcox, W. J., Jr

Winkel, R. A.

Oak Ridge National Laboratory

White, J. C.

Oak Ridge Y-12 Plant

Adams, T. T. (5)

Andrews, R. E.

Barton, T. H., Jr (5)

Bernander, N. K.

Briscoe, O. W.

Burditt, R. B.

Burkhart, L. E:

Denny, A. (2)

Dill, M. S.

Ferguson, M. R. (5)

Franklin, J. C.

Hemphill, L. F. Jones, F. W.

Kahl, K. G.

Keith, Alvin

McLendon, J. D.

Mitchel, G. W.

Morrow, R. W.

Schreyer, J. M.

Smith, H. F., Jr

Smith, J. H.
Smith, R. D.

Stephens, L. A.

Weathersby, W. E.

Yaggi, W. J.

$Y-12$ Central Files (5)

$Y-12$ Central Files (master copy)

$Y-12$ Central Files (route)

$Y-12$ Central Files (Y-12RC)

Paducah Gaseous Diffusion Plant

Levin, R. W.

In addition, this report is distributed in accordance with the category UC-4, Chemistry, as given in the USAEC Standard Distribution Lists for Unclassified Scientific and Technical Reports, TID-4500. 